\title{
Target Nodal Tumor Identification
}

National Cancer Institute

\section{Source}

National Cancer Institute. Target Nodal Tumor Identification. NCI Thesaurus. Code C103443.

The identification of a target tumor located at or near the lymph node. 